\title{
THE SPECTRUM AND PROGNOSIS OF AIDS- DEFINING ILLNESSES IN CAPE TOWN
}

\author{
M Badri, $M S c$ Med \\ Gary Maartens, $F C P$ \\ Linda-Gail Bekker $P h D$ \\ Robin Wood, FCP \\ Desmond Tutu HIV Centre, Institute of Infectious Diseases and Molecular Medicine, \\ and Department of Clinical Pharmacology, Faculty of Health Sciences, University of Cape Town
}

\begin{abstract}
Objectives. To describe the incidence, spectrum and prognosis of AIDS-defining illnesses (ADI) in patients without access to antiretroviral therapy (ART).

Design. Prospective cohort study.

Subjects. 1215 HIV-infected patients attending adult HIV clinics affiliated to the University of Cape Town in the New Somerset and Groote Schuur Hospitals from 1992 to 2000.

Main outcome measures. Incidence rate (IR) of ADls and survival after the development of ADI.

Results. During follow-up, $430 \mathrm{ADIs}$ occurred (IR $=21.3$ cases per 100 patient-years (PYs)). IR varied according to CD4 count, with

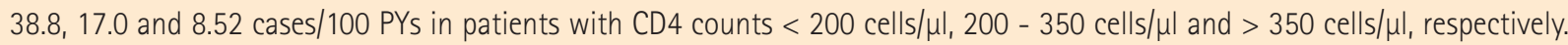
Tuberculosis (TB) was the commonest ADI, followed by candidiasis of the oesophagus/trachea/bronchi. IRs for chronic herpes simplex ulcers, HIV wasting, Pneumocystis carinii pneumonia and Kaposi's sarcoma were $>1.00$ cases/100 PYs. TB was diagnosed in all CD4 strata, and was the only illness to occur commonly above 200 cells/ $\mu$ l. The median CD4 counts within 6 months of diagnosis of $A D I$ ranged from 138 cells/ $/ \mu$ for TB to 17 cells/ $\mu$ l for cryptococcosis. Overall, median time to death from date of diagnosis was 18 months, and ranged from 24.1 months for patients diagnosed with TB to 6 months for those diagnosed with cytomegalovirus.

Conclusions. HIV-infected patients with no access to ART in Cape Town are at high risk of AIDS-defining illnesses. This study provides useful data for designing therapeutic interventions for preventing these infections.
\end{abstract}

HIV infection is characterised by progressive immune suppression, which eventually results in the development of opportunistic diseases. ${ }^{1-3}$ The spectrum of these infections varies across the world, and is partially determined by the organisms that are prevalent in the community.

The spectrum of severe HIV-related diseases in sub-Saharan Africa is characterised by an abundance of virulent pathogens such as Mycobacterium tuberculosis, Streptococcus pneumoniae and Salmonella spp., ${ }^{4,5}$ Pneumocystis carinii pneumonia (PCP) is uncommon, and avirulent organisms such as cytomegalovirus (CMV) and M. avium complex are seldom found. ${ }^{4.5}$ Tuberculosis (TB), bacterial infections and malaria are the leading causes of HIV-related morbidity across sub-Saharan Africa. In studies reporting CD4 count, the range of cell counts at the time of diagnosis of severe HIV-related diseases is wide. ${ }^{4,5}$

While the spectrum of severe HIV-related diseases in industrialised countries is well described, few published studies exist describing the incidence and prognosis of HIV-related diseases in Africa, and the level of immune suppression at which these diseases occur. Most existing studies are of crosssectional design, and is difficult to compare them owing to differences in referral patterns, study population, criteria for HIV testing, diagnostic methods, and the disease reported. ${ }^{6}$ Sound incidence data on severe HIV-related events are important for designing preventive or curative therapeutic intervention.

\section{METHODS}

The objectives of this analysis were to estimate the incidence of AIDS-defining illness (stratified by CD4 count and WHO clinical stage) and survival after the development of AIDS-defining illness, and to describe the distribution of the CD4 count within 6 months of the onset of AIDS-defining illnesses in HIVinfected patients with no access to antiretroviral therapy (ART).

The analysis was based on the Cape Town AIDS Cohort (CTAC), which comprises patients from the wide socio-demographic 
spectrum of the Western Cape. CTAC is based on patients attending public sector HIV health care services at New Somerset Hospital (NSH) and Groote Schuur Hospital (GSH), which are affiliated to the University of Cape Town. For the purpose of this analysis, patients presenting with an AIDSdefining illness at their initial clinic visit or receiving any form of ART were excluded.

Data on the CTAC patients were collected prospectively from 1992. Routine demographic, clinical and laboratory data were collected using a standard computerised format. Patients presented to the clinic approximately 3 - 6-monthly or more frequently if clinically indicated. At each visit, patients were examined for manifestations of HIV/AIDS-related illness and staged using the World Health Organization (WHO) criteria. ${ }^{7}$ HIV diagnosis was confirmed by enzyme-linked immunosorbent assay (ELISA) and confirmed with Western blot (or subsequently a second ELISA) on two different blood specimens. The CD4 count was measured approximately bi-annually, using flow cytometry (Beckman Coulter ${ }^{\circledR}$, Miami, Fla, USA). Vital status data were acquired from the inpatient records, via notification by family or the patient's general practitioner, or by reviewing local death registries. The analysis was carried using Epi Info (version 6.0; CDC, Atlanta, Ga, USA) and STATISTICA (release 6.6, Tulsa, Oklahoma, USA).

\section{AIDS-FREE SURVIVAL AND RISK OF DEATH FROM ONSET OF AIDS}

The Kaplan-Meier method was used to plot AIDS-free survival curves by WHO stage and CD4 count from the initial clinic visit date to the date of onset of an AIDS-defining illness. The same method was used to measure risk of death from the onset of AIDS. The analysis was further stratified by specific illness. CD4 count was measured \pm 6 months from the initial clinic visit, if not available at the date of the initial clinic visit. CD4 count was categorised as $<200,200-350$ and $>350$ cells/ $\mu$ l.

\section{INCIDENCE OF AIDS-DEFINING ILLNESSES}

The incidence rate $(I R)$ for each diagnosis was calculated by dividing the number of new diagnoses of the AIDS-defining illness that occurred after entry into the cohort by the total number of the person-years (PYS) of the cohort. The analysis was further stratified by baseline CD 4 count. The time spent in each CD4 count stratum was summed, yielding PYs by CD4 count stratum, and the incidence rate of each AIDS-defining illness was calculated as the number of new cases occurring while in a given $\mathrm{CD} 4$ count stratum, divided by the total number of PYs of observation in that CD4 count stratum. For each AIDSdefining illness the distribution of CD4 counts (within \pm 6 months of the diagnosis of the condition) was examined. Allcause mortality was estimated for each AIDS-defining illness using the Kaplan-Meier method. Follow-up was continued until death, date last seen in the clinic or end-point of the study (31 December 2000). In this analysis, all sites of TB diagnosis (pulmonary, extrapulmonary or disseminated) were included in one group.

\section{RESULTS}

\section{STUDY SAMPLE}

The study included 1215 patients who did not use ART during follow-up and had no AIDS-defining illness before the initial clinic visit. The baseline characteristics of these patients are described in Table I. The cohort consists mostly of young indigent patients with a wide clinical and immune suppression spectrum. Approximately 50\% of these patients received prophylactic cotrimoxazole at some point of their follow-up.

\section{TABLE I. BASELINE CHARACTERISTICS OF THE COHORT}

\begin{tabular}{|c|c|}
\hline Age (mean \pm SD) (yrs) & $31.3( \pm 8.89)$ \\
\hline \multicolumn{2}{|l|}{ CD4 count } \\
\hline$<200$ cells/ $/ \mu \mid$ & 415 (34.2\%) \\
\hline $200-350$ cells/ $/ \mu l$ & $319(26.3 \%)$ \\
\hline$>350$ cells/ $/ \mu l$ & $446(36.7 \%)$ \\
\hline Not done & $35(2.8 \%)$ \\
\hline Median (interquartile range) & $276.5(143.5-437.0)$ \\
\hline \multicolumn{2}{|l|}{ WHO stage } \\
\hline Stage I & $547(45 \%)$ \\
\hline Stage II & $210(17.3 \%)$ \\
\hline Stage III & $458(37.7 \%)$ \\
\hline Use of cotrimoxazole & $644(53.0 \%)$ \\
\hline \multicolumn{2}{|l|}{ Gender } \\
\hline Female & $634(52.2 \%)$ \\
\hline Male & $581(47.8 \%)$ \\
\hline \multicolumn{2}{|l|}{ Socioeconomic status } \\
\hline Low & $872(71.8 \%)$ \\
\hline High & $343(28.2 \%)$ \\
\hline
\end{tabular}

\section{AIDS-FREE SURVIVAL}

Median time to occurrence of an AIDS-defining illness varied according to baseline CD4 count (ranging from 63 months for patients with CD4 count $>350$ cells/ $\mu$ l to 18 months in those with CD4 count $<200$ cells/ $\mu l$ ) and WHO stage (ranging from 56 months for patients with WHO stage I to 18 months in those with WHO stage III) (Fig. 1).

\section{INCIDENCE OF AIDS-DEFINING ILLNESSES}

During a median 1.66 years of follow-up, 430 AIDS-defining illnesses occurred ( $\mathrm{R}=21.3$ cases per $100 \mathrm{PY}$, 95\% confidence interval (CI) 19.6 - 23.2) (Table II). Of these illnesses, 255 occurred in patients with CD4 count $<200$ cells/ $\mu \mathrm{I}(\mathrm{IR}=38.8$ cases per $100 \mathrm{PYS}, 95 \% \mathrm{Cl} 35.0$ - 42.6), 108 illnesses in patients

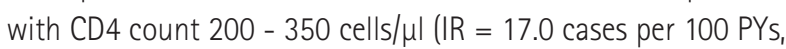
$95 \% \mathrm{Cl} 14.2-20.2)$, and 59 in patients with CD4 count $>350$

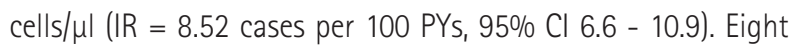
illnesses occurred in $30.1 \mathrm{PYs}$ of follow-up in patients with unknown CD4 count ( $\mathrm{R}=26.7,95 \% \mathrm{Cl} 12.3-45.9$ cases per $100 \mathrm{PYs}$ ). Incidence ranged from 10.6 cases per $100 \mathrm{PYS}$ for TB to 0.05 cases per 100 PYs for endemic mycosis. 


\section{CD4 COUNT AT DIAGNOSIS OF AIDS-DEFINING ILLNESSES}

At (or \pm 6 months of) the date of diagnosis, median CD4 counts ranged from 138 cells/ $\mu$ l for TB cases to 17 cells/ $\mu$ l for cryptococcosis (Fig. 2).

\section{SURVIVAL FOLLOWING DIAGNOSIS OF AIDS-DEFINING ILLNESSES}

Overall, median time to death from date of diagnosis was 18 months. Median survival ranged from 24.1 months for patients diagnosed with TB to 6 months for those diagnosed with CMV (Table III).

\section{DISCUSSION}

This study reported high rates of AIDSdefining illnesses among HIV-infected patients living in Cape Town with no access to highly active antiretroviral therapy (HAART). The IR of these illnesses was high at low CD4 cell strata,

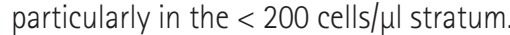
TB was the commonest illness, followed by candidiasis of the oesophagus/ trachea/bronchi or lungs. Herpes simplex virus (HSV) infection, wasting, Pneumocystis carinii pneunomia (PCP) and
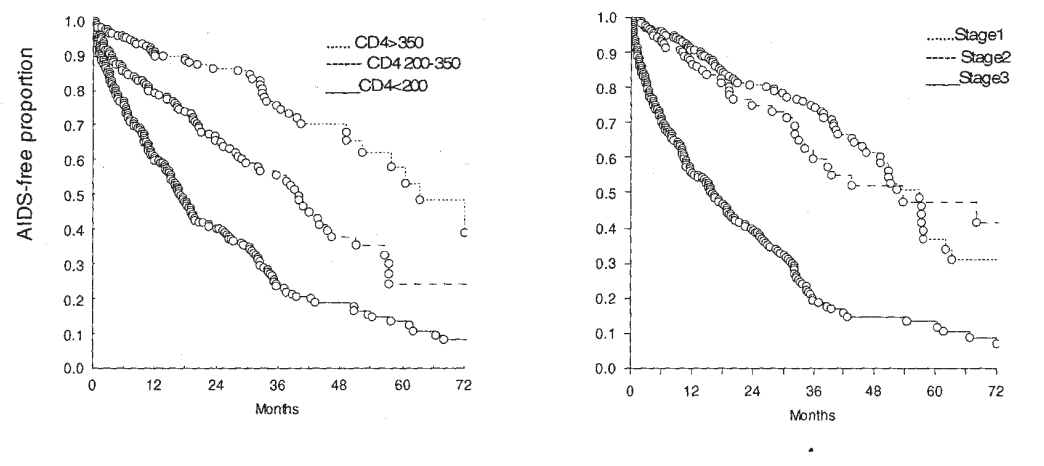

Median AIDS-free survival (months)

\begin{tabular}{cccccc} 
CD4 $>350$ & CD4 $200-350$ & CD4 $<200$ & Stage 1 & Stage 2 & Stage 3 \\
\hline 63 & 41 & 18 & 56 & 39 & 18
\end{tabular}

Fig. 1. Kaplan-Meier probabilities of AIDS-free survival according to baseline CD4 count category and WHO stage.

Kaposi's sarcoma had an IR $>1.00$ cases per 100 PYs. Disseminated mycosis, progressive multifocal leukoencephalopathy and lymphoma were rare. TB was diagnosed in all CD4 strata, and was the only illness to occur commonly above

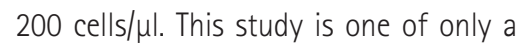
few that have assessed the incidence of the AIDS-defining illnesses in Africa, stratified both by CD4 count and WHO clinical stage. However, the pre- ponderance of $\mathrm{TB}$ and the level of immune suppression at which it occurs, and the overall spectrum of illnesses, is consistent with other reports from the region. ${ }^{5,8-10}$ Of note is the fact that most of the illnesses diagnosed in this cohort are preventable or are amenable to treatment. The incidence estimates and time to AIDS according to baseline CD4 count and WHO stage, and survival following the onset of each AIDS-

\begin{tabular}{|c|c|c|c|c|c|c|c|c|c|}
\hline \multirow[t]{2}{*}{ Illness } & \multicolumn{2}{|c|}{$\begin{array}{c}\text { Overall } \\
\text { (2014.8 PYs) }\end{array}$} & \multicolumn{2}{|c|}{$\begin{array}{c}<200 \text { cells } / \mu l \\
(657.5 \text { PYs })\end{array}$} & \multicolumn{2}{|c|}{$\begin{array}{c}200-350 \text { cells } / \mu l \\
(635.1 \text { PYs })\end{array}$} & \multicolumn{2}{|c|}{$\begin{array}{c}>350 \text { cells } / \mu l \\
(692.1 \mathrm{PYs})\end{array}$} & \multirow[t]{2}{*}{ N/A } \\
\hline & No. & Incidence & No. & Incidence & No. & Incidence & No. & Incidence & \\
\hline 1 Tuberculosis & 214 & 10.6 & 111 & 16.88 & 62 & 9.76 & 39 & 5.64 & 2 \\
\hline 2 Candidiasis of $0 / T / B / L$ & 57 & 2.83 & 40 & 6.08 & 13 & 2.05 & 2 & 0.29 & 2 \\
\hline 3 HSV & 27 & 1.34 & 19 & 2.89 & 7 & 1.10 & 1 & 0.14 & 0 \\
\hline 4 Wasting & 27 & 1.34 & 15 & 2.28 & 6 & 0.94 & 6 & 0.87 & 0 \\
\hline 5 РCP & 24 & 1.19 & 15 & 2.28 & 6 & 0.94 & 3 & 0.43 & 0 \\
\hline 6 Kaposi's sarcoma & 23 & 1.14 & 17 & 2.59 & 2 & 0.31 & 3 & 0.43 & 1 \\
\hline 7 Cryptococcosis & 13 & 0.65 & 9 & 1.37 & 2 & 0.31 & 1 & 0.14 & 1 \\
\hline 8 Encephalopathy & 11 & 0.55 & 5 & 0.76 & 4 & 0.63 & 1 & 0.14 & 1 \\
\hline 9 Cryptosporidiosis & 10 & 0.50 & 8 & 1.22 & 0 & 0 & 1 & 0.14 & 1 \\
\hline \multicolumn{10}{|l|}{10 Disseminated atypical } \\
\hline mycobacteria & 8 & 0.40 & 5 & 0.76 & 3 & 0.47 & 0 & 0 & 0 \\
\hline $11 \mathrm{CMV}$ & 6 & 0.30 & 4 & 0.61 & 1 & 0.16 & 1 & 0.14 & 0 \\
\hline 12 Lymphoma & 4 & 0.20 & 4 & 0.61 & 0 & 0 & 0 & 0 & 0 \\
\hline 13 Toxoplasmosis & 3 & 0.15 & 3 & 0.46 & 0 & 0 & 0 & 0 & 0 \\
\hline $14 \mathrm{PML}$ & 2 & 0.10 & 0 & 0 & 2 & 0.31 & 0 & 0 & 0 \\
\hline 15 Mycosis & 1 & 0.05 & 1 & 0.15 & 0 & 0 & 0 & 0 & 0 \\
\hline Total & 430 & 21.34 & 256 & 38.94 & 108 & 17.01 & 58 & 8.38 & 8 \\
\hline
\end{tabular}


TABLE III. KAPLAN-MEIER PROBABILITIES OF SURVIVAL FOLLOWING DIAGNOSIS.

\begin{tabular}{|lcccccccccccc|c|}
\hline $\begin{array}{l}\text { Condition } \\
\text { Median }\end{array}$ & All & TB & WAS & KS & HSV & PCP & CRYPS & CAND & Enc & Lymph & CRYPO & ATYP & CMV \\
survival & & 24.1 & 22.2 & 17.8 & 17 & 14 & 13.9 & 9.5 & 8.6 & 7.6 & 6.5 & 6.4 & 6.1 \\
\hline
\end{tabular}

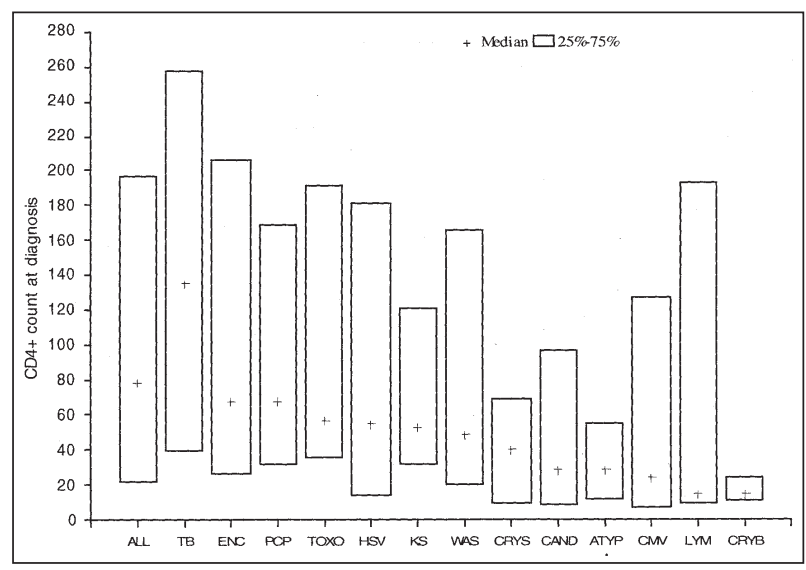

$\mathrm{TB}=$ all forms of $\mathrm{TB} ; \mathrm{ENC}=\mathrm{HIV}$ encephalopathy; $\mathrm{PCP}=$ Pneumocystis carinii pneumonia; $\mathrm{TOXO}=$ toxoplasmosis; $\mathrm{HSV}=$ herpes simplex virus; KS $=$ Kaposi's sarcoma; WAS = HIV wasting syndrome; CRYS = cryptosporidiosis with diarrhoea $>1$ month; CAND = candidiasis of the oesophagus, trachea, bronchi or lungs; ATYP $=$ disseminated atypical mycobacteriosis; $C M V=$ cytomegalovirus; $L Y M=$ lymphoma; $C R Y B=$ extrapulmonary cryptococcosis.

Fig. 2. CD4 count distribution at (or \pm 6 months of) the date of diagnosis.

defining illness calculated in this study, are useful data for designing and assessing the outcome of therapeutic interventions for preventing and treating these infections.

Survival after AIDS in Africa may be shorter than in industrialised countries. This may be due to high prevalence of virulent pathogens in the environment and lack of access to health care. In a recent review, Holmes et al..$^{5}$ observed that in sub-Saharan Africa, TB and bacterial infections are the major cause of morbidity and mortality among hospitalised patients. Bacteraemia, particularly caused by non-typhoid salmonellae and S. pneumoniae, and associated with cryptosporidia and Isospora belli, are the most frequently isolated pathogens. Nontyphoid salmonellae and Shigella species are also commonly isolated when stool cultures are performed. Cerebral toxoplasmosis, and meningitis due to Cryptococcus neoformans, tuberculosis and bacterial pathogens, are the most frequent neurological infections. Infections with atypical mycobacteria, Pneumocystis carinii and CMV are rare. ${ }^{5}$ They also found that, compared with industrialised countries, death occurs at a higher range of CD4 counts, although still in the range consistent with advanced disease.

The findings of this study have important implications for health care management of HIV-infected patients. Very few infections preventable by cotrimoxazole occurred at CD 4 counts $>200$ cells/ $/ \mu$. This suggests a limited beneficial effect for prophylactic cotrimoxazole in patients with CD4 counts at this level. The high incidence of TB across the different CD4 count strata indicates that preventive therapy with isoniazid should be considered early in the course of HIV disease.
This study had the following limitations. Cause of death was not ascertained, and therefore all-cause mortality was reported. As such, we are unable to exclude non-HIV-related causes of death. Median follow-up of 19.9 months is relatively short and reflects the difficulty of maintaining long follow-up in this setting. It is therefore possible that the actual incidence rate of the various infections reported among this cohort might have been underestimated.

In conclusion, in HIV-infected patients without access to HAART in Cape Town, the overall risk of AIDS-defining illnesses is high and increases with lower CD4 counts and more advanced WHO clinical stage. Early prevention and treatment of these infections will result in large health benefits. Guidelines for therapeutic interventions for prevention of AIDS-defining illness, including ART, in this region should be tailored according to the spectrum and epidemiology of these infections.

This study was funded by an academic research grant from Secure the Future, Bristol-Myers and Squibb, and partially funded by CIPRA-SA (National Institutes of Health, USA). The authors acknowledge invaluable assistance in data acquisition from Desmond Tutu HIV Research Centre staff, Dr R Kirsten (medical superintendent), M Goliath, R Solomons and J Preez of Somerset Hospital, and M Hassan and J Daniels of the Cape Town Metropolitan Council.

\section{REFERENCES}

1. Masur $H_{1}$ Michelis MA, Greene JB, et al. An outbreak of communityacquired Pneumocystis carinii pneumonia, initial manifestations of cellular immune dysfunction. N Engl Med 1981; 305: 1431-1438.

2. Gottlieb MS, Schroff R, Schanker HM et al. Pneumocystis carinii pneumonia and mucosal candidiasis in previously healthy homosexual men. N Engl J Med 1984; 305: 1425-1431.

3. Siegal FP, Lopez C, Hammer GS, et al. Severe acquired immunodeficiency in male homosexuals manifested by chronic perianal ulcerative herpes simplex lesions. N Engl J Med 1984; 305: 1439-1444.

4. Maartens G. Opportunistic infections associated with HIV infection in Africa. Oral Dis 2002; 8: 76-79.

5. Holmes CB, Losina E, Walensky RP, Yazdanpanah Y, Freedberg KA. Review of human immunodeficiency virus type 1-related opportunistic infections in sub-Saharan Africa. Clin Infect Dis 2003; 36: 652-662.

6. Grant AD, Kaplan JE, De Cock KM. Preventing opportunistic infections among human immunodeficiency virus-infected adults in African countries. Am J Trop Med Hyg 2001; 65: 810-821.

7. World Health Organization. Acquired immunodeficiency syndrome (AIDS): interim proposal for a WHO staging system for HIV infection and disease. Wkly Epidemiol Rec 1990, 65: 221-224.

8. Mukadi $Y_{1}$ Perriens JH, St. Louis $M E_{\text {, }}$ et al. Spectrum of immunodeficiency in HIV-1-infected patients with pulmonary tuberculosis in Zaire. Lancet 1993; 342: 143-146.

9. Grant A, Sidibe K, Domoua $K_{1}$ et al. Spectrum of disease among HIVinfected adults hospitalised in a respiratory medicine unit in Abidjan, Cote d'Ivoire. Int J Tuberc Lung Dis 1998;11: 926-934.

10. Corbett EL, Churchyard GJ, Charalambos S, et al. Morbidity and mortality in South African gold miners: impact of untreated disease due to human immunodeficiency virus. Clin Infect Dis 2002; 34: 1251-1258. 